\title{
Alcohol Use and Risky Sexual Behavior among College Students and Youth: Evaluating the Evidence*
}

\author{
M. LYNNE COOPER, PH.D. \\ Department of Psychology, 210 McAlester Hall, University of Missouri-Columbia, Columbia, Missouri 65211
}

\begin{abstract}
Objective: To evaluate the empirical associations between alcohol use and risky sex at two levels of analysis. Global associations test whether individuals who engage in one behavior are more likely to engage in the other, whereas event-specific associations test whether the likelihood of engaging in one behavior on a given occasion varies as a function of engaging in the other on that same occasion. Method: Studies examining the association between drinking and risky sex in samples of college students and youth were reviewed. Those published in the past 10 years and using event-level methodology or random sampling were emphasized. Results: Findings were generally consistent across levels of analysis, but differed across types of risky behaviors. Drinking was strongly related to the decision to have sex and to indiscriminate forms of risky sex (e.g., having multiple or casual sex partners), but was in-
\end{abstract}

consistently related to protective behaviors (e.g., condom use). Moreover, the links among alcohol use, the decision to have sex and indiscriminate behaviors were found in both between-persons and within-persons analyses, suggesting that these relationships cannot be adequately explained by stable individual differences between people who do and do not drink. Analysis of event characteristics showed that drinking was more strongly associated with decreased protective behaviors among younger individuals, on first intercourse experiences and for events that occurred on average longer ago. Conclusions: Future efforts aimed at reducing alcohol use in potentially sexual situations may decrease some forms of risky sex, but are less likely to affect protective behaviors directly. (J. Stud. Alcohol, Supplement No. 14: 101-117, 2002)
$\mathrm{T}$ HE MAJORITY of young people $(75 \%$ of boys and $60 \%$ of girls; Alan Guttmacher Institute, 1994) have had sex by the time they graduate from high school, and the majority of those who have not will have their first sexual experience while in college. Sexual experience during this developmental period, however, tends to be sporadic, furtive and poorly managed (for reviews, see Brooks-Gunn and Paikoff, 1997; Miller et al., 1993). Thus even sexually experienced students enter college with much to learn in the sexual arena. College life, with its greatly expanded opportunities for self-governance and independence, provides an important new context in which young people learn to manage their sexual relationships and their sexuality.

Like most learning processes, learning to manage one's sexuality provides opportunities for mastery and growth, but also poses risk of emotional trauma and pain and of costly physical health consequences such as unplanned pregnancy, sexually transmitted diseases and, in rare cases, even death. To evaluate the extent to which drinking among collegiate youth is associated with increased participation in sexual behaviors that lead to negative outcomes such as these, this article reviews and evaluates empirical research on the link between alcohol use and high-risk sexual behavior to determine whether and, if so, to what extent the

\footnotetext{
* Preparation of this article was supported by National Institute on Alco-
} hol Abuse and Alcoholism grant R01-08047. two behaviors reliably covary among youth in general and college youth in particular.

This review is organized in three parts. The first part provides relevant background and contextual information, including a brief overview of theoretical explanations for the link between drinking and risky sexual behavior. The second part summarizes the data on prevalence of drinking and sexual behavior among college students and then reviews and evaluates the evidence on the co-occurrence or overlap of the two behaviors. The issue of overlap is addressed at two levels of analysis in this review. The first level examines the extent to which an individual who engages in one behavior is more likely to engage in the other (called global overlap by Leigh and Stall, 1993). The second level examines whether a person who engages in one behavior on a specific occasion is more likely to engage in the other behavior on that same occasion (situational overlap). To enhance the generalizability of findings from this review, data from studies using randomly selected samples are emphasized where possible. To ensure the relevance of the data to contemporary drinking and sexual practices, findings from more recent studies (primarily those conducted in the past 10 years) also are emphasized. Finally, the third part concludes with a summary of findings and offers recommendations for intervention and research.

For the purposes of the present review, high-risk sexual behavior is defined as any behavior that increases the probability of negative consequences associated with sexual contact, including AIDS or other sexually transmitted diseases 
(STDs) and unplanned pregnancy. These behaviors are considered in two broad categories: (1) indiscriminate behaviors, including having multiple partners; having risky, casual or unknown partners; and failure to discuss risk topics prior to intercourse and (2) failure to take protective actions, such as use of condoms and birth control. Alcohol effects on the decision to have intercourse is also examined in that the occurrence of intercourse per se can be viewed as the ultimate root cause of sexual risk taking. Frequency of intercourse is not, however, treated as a risk behavior. Although more frequent intercourse, all other things being equal, increases risk of exposure (de Vincenzi, 1994), intercourse frequency is significantly associated with having an exclusive sexual partner (Cooper et al., 1998). Thus intercourse frequency, analyzed without reference to relationship status (as is typically the case), is an ambiguous risk indicator at best.

\section{Background and Overview}

\section{Adverse consequences of sexual risk taking on college campuses}

Extant data suggest that negative consequences associated with sexual risk taking are common on college campuses. According to results of a recent nationwide survey, for example, $15 \%$ of college students have been pregnant or gotten a partner pregnant (Douglas et al., 1997). Statewide studies conducted in California (Patrick et al., 1997) and Texas (Wiley et al., 1996) found similar overall rates (14\% and $22 \%$, respectively). Moreover, across all studies, women reported higher rates than men (from $20 \%$ to $40 \%$ ) (Table 1).

A nationwide study of Canadian college freshmen found that nearly $6 \%$ of sexually experienced students had been diagnosed by a doctor with an STD at least once (MacDonald et al., 1990). Rates among U.S. college students range from $12 \%$ of sexually experienced students in California (Patrick et al., 1997) to nearly $25 \%$ on a midwestern campus (Reinisch et al., 1995). The higher rates found in U.S. studies may reflect cultural, geographic or methodological differences, but at least partly reflect the younger age of students in the Canadian sample. Across all studies, rates of STDs were higher (in some cases, nearly twice as high) among women than men. Finally, estimates of HIV infection rates (from seroprevalence studies) range from $0.0 \%$ to $1.0 \%$ on individual campuses, with an average rate across 19 U.S. campuses of $0.2 \%$ (Gayle et al., 1990; see also Kotloff et al., 1991).

In sum, these data suggest that although aggregate rates of HIV infection are low among college students, the rates on some campuses are alarmingly high: as high as 1 in 100 students. Moreover, the experience of pregnancies and other STDs appears relatively common on college campuses, par- ticularly among women. Considered together, these data indicate that a substantial minority of college students suffer one or more adverse consequences associated with sexual risk taking and support the need to identify factors, particularly modifiable ones like alcohol use, that might contribute to sexual risk taking in this population.

\section{Alternative explanations for the link between alcohol use and risky sexual behavior}

Targeting drinking proximal to intercourse as part of a strategy to reduce sexual risk taking will prove effective, however, only to the extent that drinking causally promotes risky behaviors. Although alcohol is widely assumed to cause such behaviors, a number of plausible alternative models exist that might account for their relationship (Cooper, 1992; Halpern-Felsher et al., 1996), only some of which posit a causal effect for alcohol. The two most widely endorsed models are briefly described below.

Acute causal effects of alcohol. The first model assumes that the acute effects of alcohol intoxication cause one to take sexual risks that otherwise would not be taken. At least two plausible mechanisms have been theorized to underlie this effect. According to alcohol myopia theory (Steele and Josephs, 1990), alcohol disinhibits behavior primarily as a result of its pharmacologic effects on information processing. By reducing the scope and efficiency of information processing, simple, highly salient cues that instigate behavior (e.g., sexual arousal) continue to be processed, whereas more distal and complex cues that would ordinarily inhibit behavior (e.g., the possibility of getting AIDS) are no longer adequately processed. Accordingly, alcohol is hypothesized to have its strongest effects when a behavior is controlled by instigatory and inhibitory cues that are strong and nearly equal in force. When instigatory cues are strong and inhibitory cues are weak, the behavior is likely to occur regardless of the individual's sobriety. Under the reverse circumstance, the behavior is unlikely to occur, again regardless of the individual's sobriety. Thus only in situations where both sets of cues would otherwise be strong should the reduced processing of inhibitory cues lead to more extreme (or different) social behavior.

In contrast, expectancy models posit that an individual's behavior after drinking is driven by preexisting beliefs about alcohol's effects on behavior, in the manner of a self-fulfilling prophecy (Lang, 1985). Thus individuals who believe that alcohol promotes risky sexual behavior should be more likely to engage in risky behaviors when they drink than those who do not hold these beliefs. Expectancy formulations thus indicate that the strength and nature of individually held beliefs about alcohol's effects should moderate the acute effects of alcohol on sexual risk taking. In short, although these two theories differ in the factors hypothesized to moderate the effects of alcohol on risky behav- 
TABLE 1. Estimates (from population-based studies) of sexual experience and alcohol use with sex among college students

\begin{tabular}{|c|c|c|c|c|c|c|c|}
\hline Study & $\begin{array}{l}\% \text { ever had } \\
\text { sex/anal sex }\end{array}$ & $\begin{array}{l}\% \text { had sex } \\
\text { (recent past) }\end{array}$ & $\begin{array}{l}\text { No. sexual } \\
\text { partners }\end{array}$ & $\mathrm{BC}$ use & Condom use & Alcohol use with sex & $\begin{array}{c}\% \text { ever pregnant/ } \\
\text { had STD }\end{array}$ \\
\hline \multicolumn{8}{|l|}{ Nationwide studies } \\
\hline Douglas et al. (1997) & $80 / \mathrm{NR}$ & $\begin{array}{l}62(3 \mathrm{Mo}) \\
55(30 \mathrm{D})\end{array}$ & $26 \% \geq 6 \mathrm{LT}$ & 44\%@LS & $\begin{array}{l}38 \% @ \text { LS } \\
37 \% \text { always } / \text { most } \\
\text { of time }\end{array}$ & 19\%@LS & $15 / \mathrm{NR}$ \\
\hline MacDonald et al. (1990) & $71 / 17$ & NR & $\begin{array}{l}31 \% \geq 5 \mathrm{LT} \\
14 \%>10 \mathrm{LT}\end{array}$ & NR & $\begin{array}{l}28 \% \text { never } \\
23 \% \text { always }\end{array}$ & NR & $\mathrm{NR} / 6$ \\
\hline Wechsler et al. (1994) & $\mathrm{NR} / \mathrm{NR}$ & NR & NR & NR & NR & $\begin{array}{l}\text { (1) } 19 \% \text { drank before } \\
\text { unplanned sex } \geq 1 \\
\text { time in past } 12 \text { Mo } \\
\text { (2) } 10 \% \text { drank before } \\
\text { unsafe sex } \geq 1 \text { time } \\
\text { past } 12 \mathrm{Mo}\end{array}$ & $\mathrm{NR} / \mathrm{NR}$ \\
\hline $\begin{array}{l}\text { Wechsler et al. (1998, } \\
\left.2000^{a}\right)\end{array}$ & 73/NR & $72(30 \mathrm{D})$ & $\begin{array}{l}6 \%>1 \\
\text { past } 30 \mathrm{D}\end{array}$ & NR & $\begin{array}{l}24 \% \text { never } \\
40 \% \text { always }\end{array}$ & $\mathrm{NR}$ & NR/NR \\
\hline \multicolumn{8}{|l|}{ Statewide or regional studies } \\
\hline DiLorio et al. $(1998)^{b}$ & $\mathrm{NR}^{c} / \mathrm{NR}$ & $81(3 \mathrm{Mo})$ & $\begin{array}{l}54 \% \geq 2 \text { past } \\
12 \text { Mo }\end{array}$ & NR & $36 \%$ never/sometimes & $\begin{array}{l}34 \% \text { ever drank } \\
\text { before sex }\end{array}$ & NR/NR \\
\hline Lewis et al. (1996) & $84 / \mathrm{NR}$ & NR & $\begin{array}{l}18 \%>1 \mathrm{LT}^{d} \\
19 \% \geq 10 \mathrm{LT}\end{array}$ & 22\%@LS & 48\%@LS & NR & $\mathrm{NR} / \mathrm{NR}$ \\
\hline O’Leary et al. (1992) & $\mathrm{NR} / \mathrm{NR}$ & NR & NR & NR & $\begin{array}{l}\mathrm{M}=6.6 \text { times had sex } \\
\text { w/o condom past } 2 \mathrm{Mo}\end{array}$ & $\begin{array}{l}\mathrm{M}=1.9 \text { times drank } \\
\text { before sex past } 2 \mathrm{Mo}\end{array}$ & $\mathrm{NR} / \mathrm{NR}$ \\
\hline Patrick et al. (1997) & $71 / \mathrm{NR}$ & 74 (3 Mo) & $\begin{array}{l}76 \%>1 \mathrm{LT} \\
18 \% \geq 10 \mathrm{LT}\end{array}$ & 41\%@LS & 41\%@LS & 22\%@LS & $14 / 12$ \\
\hline Wiley et al. (1996) & $82 / \mathrm{NR}$ & NR & $\begin{array}{l}44 \% \geq 1 \text { past } \\
3 \mathrm{Mo}\end{array}$ & 26\%@LS & 40\%@LS & 30\%@LS & $22 / \mathrm{NR}$ \\
\hline \multicolumn{8}{|l|}{$\begin{array}{l}\text { Studies on individual } \\
\text { college campuses }\end{array}$} \\
\hline Baldwin et al. (1992) & $80 / 15$ & NR & $\begin{array}{l}\mathrm{M}=2.0 \text { past } \\
12 \mathrm{Mo}\end{array}$ & NR & $\begin{array}{l}\mathrm{M}=31 \% \text { time used } \\
\text { condom w/sex past } \\
3 \mathrm{Mo}\end{array}$ & NR & $\mathrm{NR} / \mathrm{NR}$ \\
\hline Hale et al. (1993) & $84 / \mathrm{NR}$ & NR & $\begin{array}{l}35 \%>1 \text { past } \\
12 \mathrm{Mo} \\
19 \%>10 \mathrm{LT}\end{array}$ & $\begin{array}{l}16 \% @ \text { FS } \\
\text { (pill only) }\end{array}$ & 36\%@FS & NR & $40^{e} / 19$ \\
\hline Pepe et al. (1993) & $62 / \mathrm{NR}$ & NR & $10 \% \geq 3 \mathrm{LT}$ & NR & NR & NR & NR/NR \\
\hline Reinisch et al. (1995) & $76 / 18$ & NR & $\begin{array}{l}\mathrm{M}=6.9 \mathrm{LT} \\
\mathrm{M}=2.2 \text { past } \\
12 \mathrm{Mo} \\
37 \%>5 \mathrm{LT}\end{array}$ & 40\%@LS & 37\%@LS & NR & $\mathrm{NR} / 25$ \\
\hline $\begin{array}{l}\text { Senf and Price, Study } 1 \\
\text { (1994) }\end{array}$ & $\mathrm{NR} / \mathrm{NR}$ & NR & $\begin{array}{l}\mathrm{M}=1.6 \text { past } \\
6 \mathrm{Mo}\end{array}$ & NR & 54\%@LS & 26\%@LS & $\mathrm{NR} / \mathrm{NR}$ \\
\hline
\end{tabular}

Notes: $\mathrm{BC}=$ birth control; $\mathrm{LT}=$ lifetime; $\mathrm{LS}=$ last sex; $\mathrm{FS}=$ first sex; $\mathrm{Mo}=$ months; $\mathrm{D}=$ days; $\mathrm{M}=$ mean; $\mathrm{NR}=$ not reported. Except for the $\%$ reporting sexual experience, percentages are given as a proportion of the sexually experienced (nonvirgin) sample. Data reported for BC use reflect use of reliable methods such as condoms, the pill, or an IUD, and exclude unreliable methods such as douching and withdrawal.

${ }^{a}$ Unpublished data provided by Wechsler et al. ${ }^{b}$ Percentages were estimated from breakdowns provided by class standing. When class standing was not a significant predictor of a given outcome, a simple unweighted mean was calculated. When class standing was a significant predictor, a weighted (by class size) mean was calculated. ${ }^{c}$ All analyses were conducted among the subset of sexually experienced students who were single and between the ages of 18 and 25. It is unclear how many of the 857 students (35\% of the sample) so eliminated were dropped because they were virgins, married, out of the age range, or for a combination of these reasons. Hence, the percentage of nonvirgins in the full sample cannot be calculated. ${ }^{d}$ Values estimated from data broken down by age. ${ }^{e}$ Among females only.

iors (viz., the nature and strength of competing cues versus individually held beliefs about alcohol effects), both nevertheless attribute causality to the acute effects of alcohol intoxication and assume that these effects unfold over a brief time course.

Results of two recent studies lend strong support to the importance of instigating and inhibiting cues in the immediate situation. In one study (MacDonald et al., 2000b), male undergraduates were randomly assigned to one of three conditions (no alcohol control, placebo, intoxicated) and then divided into low and high arousal groups on the basis of their self-reported response to a film depicting a potential sexual encounter between an attractive couple. Results showed that only those subjects who were both intoxicated and aroused reported stronger intentions to have unprotected sex. Presumably, intoxicated subjects had sufficient cognitive capacity to process arousal cues, but unlike their sober counterparts, lacked sufficient capacity to process simultaneously more remote inhibiting cues. In a second study, MacDonald et al. (2000a) showed that stamping the hands 
of college students as they entered a bar with a message highlighting the threat of AIDS reduced the negative effects of alcohol on intentions to use condoms. By increasing the salience of AIDS, the hand stamp presumably facilitated retrieval of condom-related cues among intoxicated patrons who otherwise lacked the cognitive capacity to retrieve these cues. Together these studies suggest that intoxicated individuals respond to the more salient of the two sets of cues in a given situation, be they instigatory or inhibitory.

At the same time, compelling evidence also supports expectancy formulations. In a recent laboratory study (George et al., 2000), participants who believed that they had consumed alcohol (although in fact none had been consumed) reported greater sexual arousal, perceived their interaction partners as more sexually disinhibited and showed erotic slides to their partner significantly longer if and only if they also held strong beliefs about alcohol's capacity both to disinhibit and to enhance sexual experience. In other words, the mere belief that alcohol had been consumed activated preexisting beliefs about alcohol's effects, which in turn generated feelings, cognitions and behaviors in line with these beliefs.

Finally, results of a recent correlational study suggest that both expectancy and cue effects operate in real-world situations. Dermen and Cooper (2000) examined alcohol effects on condom use for three different occasions of intercourse (first ever, most recent first and last). Drinking was associated with lower rates of condom use at first intercourse, but only among those who both believed that alcohol increases sexual risk taking and were highly conflicted about using a condom on that occasion. Expectancies alone were found to moderate alcohol effects on the second occasion, whereas conflict alone moderated alcohol effects on the final occasion. Thus the best available evidence suggests that alcohol effects on sexual risk taking are likely to be conditional on individually held beliefs about alcohol's effects on sexual behavior, situation-specific contingencies controlling the behavior or a combination of the two.

Spurious model. A second alternative model invokes a third-variable explanation in which stable aspects of the individual or of his or her life situation are thought to cause both drinking and risky sex. For example, a person may engage in both behaviors to satisfy thrill or sensationseeking needs, because of poor impulse control or coping skills or in an effort to cope with negative emotions (Cooper, 1992; Leigh and Stall, 1993). Alternatively, an individual may drink and have risky sex as part of a larger lifestyle, such as being single or living in a fraternity house (Baer, 1994), where both behaviors are tacitly or, in some cases, explicitly encouraged. Extant research lends support to this perspective by showing that the same personality factors (impulsivity and negative emotionality) prospectively predict involvement in both behaviors (Caspi et al., 1997), and that parallel motivational processes underlie both behaviors (Cooper et al., 2000). A more direct test of this hypothesis was provided by two recent studies in which the relationship between measures of alcohol use and risky sexual behavior was estimated both before and after controlling for plausible third variables. In both studies, sensation seeking was found to account completely for the relationship between drinking and risky sex (Justus et al., 2000; Kalichman et al., 1996). Thus it seems plausible that, under at least some circumstances or for some individuals, the link between drinking and risky sex can be adequately explained by third variable causes.

In sum, two widely held models have been advanced to account for the relationship between drinking and risky sex. Moreover, even though these models appear to offer opposing accounts of the relationship between drinking and risky sex, empirical evidence supports both. Thus, despite commonly endorsed beliefs that alcohol causally promotes risky sexual behavior, theory and empirical data paint a more complex picture of their relationship. In the following section, studies examining the link between drinking and risky sexual behavior among college students are reviewed and evaluated in light of these models.

\section{Drinking and Risky Sex: Overlapping Behaviors among College Students?}

\section{Prevalence of both behaviors on college campuses}

As described elsewhere (O'Malley and Johnston, this supplement), the vast majority of college students drink, and a substantial minority (about $40 \%$ ) can be classified as heavy episodic (HE) drinkers (often defined as having five or more drinks on a single occasion during a specified time period, such as the past 2 weeks). Similarly, most college students are sexually experienced, and many engage in multiple forms of risky sexual behavior (Table 1). According to findings from the National College Health Risk Behavior Survey (Douglas et al., 1997), 8 of 10 college students between the ages of 18 and 24 years have ever had intercourse. Of these, $62 \%$ had recent (past 3 months) intercourse. More important, about $25 \%$ of students have had six or more lifetime sex partners, and only a minority take adequate precautions to prevent pregnancy or sexual infection. For example, 4 in 10 had used the "pill," and about as many had used a condom, at last sex. Fewer than 4 in 10 reported that either they or their partner had always used a condom in the past 30 days. Finally, in a national study of Canadian college students (MacDonald et al., 1990), 17\% reported having ever had anal sex, but fewer than $25 \%$ reported always using a condom.

Although none of the above national studies included detailed measures of indiscriminate partner choice, several 
studies conducted on individual college campuses suggest that many students exercise poor judgment in partner choice. For example, a random sample survey of students at a midwestern university found that women reported an average of three and men an average of five "one-night stands" (i.e., having sex with someone once and only once) in their lifetime (Reinisch et al., 1995). Moreover, 1 in 20 University of Maryland students reported having had sex with at least one high-risk partner (i.e., someone who had HIV or was an IV drug user, a hemophiliac, a male bisexual or a female prostitute [Kotloff et al., 1991]).

Although the above data indicate that alcohol use, sexual behavior and failures to use protection are commonplace among college students, they do not establish whether the same person engages in all of these behaviors or, more importantly, whether the likelihood of engaging in one behavior depends on involvement in another. Indeed, because of the high base rates of these behaviors, we would expect a nontrivial proportion of students both to drink and to engage in some form of risky sexual behavior by chance alone. For example, given that 9 of 10 students drink and 8 of 10 have had sex, 7 of 10 students should both drink and have had sex by chance alone. Similarly, given that 4 of 10 students are HE drinkers and 3 of 10 have had six or more sex partners, more than 1 in 10 should have engaged in both behaviors by chance alone. Thus simply demonstrating that some percentage of college students engages in both behaviors does not mean that the two behaviors are reliably linked. Existing data (reviewed next) do, however, document a reliable global association between these behaviors.

\section{Alcohol use and risky sexual behavior at the global level}

Studies examining the link between alcohol and risky sex at the global level typically ask participants about their overall involvement in some high-risk behavior and their overall frequency and quantity of alcohol use. Studies using this approach have generally found strong relationships between alcohol use and indiscriminate behaviors, but inconsistent ones between alcohol use and protective behaviors.

A national survey of more than 17,000 collegiate youth, for example, found that HE drinkers were nearly three times as likely to have had multiple sex partners in the past month than were non-HE drinkers (Wechsler et al., 1995). Similarly, a national study of more than 4,000 sexually experienced youth ages 14 to 21 years (Santelli et al., 1998) found that adjusted proportions of young men who had multiple partners in the past month rose from $23 \%$ to $61 \%$ as the number of alcohol-related behaviors increased, whereas the proportions among young women rose from $8 \%$ to $48 \%$. Based on another national study of young adults (18- to 30-year olds), Graves (1995) reported that rates of multiple partnerships were two to three times greater among HE than non-HE drinkers and were similar for men and women. In contrast to the consistent positive link between general drinking patterns and having multiple partners, $\mathrm{HE}$ and nonHE drinkers were not found to differ in rates of condom use in the previously cited study of collegiate youth (Wechsler et al., 1994). The Youth Risk Behavior Survey (a national sample of noncollege youth) also found that alcohol experience failed to discriminate condom users from nonusers at last intercourse (Lowry et al., 1994). However, in her national sample of young adults, Graves (1995) found that more frequent HE drinking was associated with lower rates of condom use.

Although several studies using convenience samples of college youth point to links between alcohol use and protective behaviors (e.g., McEwan et al., 1992), many of these studies were flawed. For example, McEwan et al. reported that the proportion of British university students who had had unprotected sex with a stranger rose from $4 \%$ among nondrinkers to $27 \%$ among heavy drinkers. Their measure, however, confounded indiscriminate partner choice with failure to use a condom, thus making it unclear whether the observed covariation with drinking pattern reflects variance due to the indiscriminate behavior or to nonuse of condoms. Other studies have reported that the frequency of drinking proximal to intercourse is positively associated with the frequency of having unprotected sex or with the number of unprotected sex episodes in a given time period (O'Leary et al., 1992). Such data are confounded, however, because both the alcohol and risky sex measures depend on frequency of intercourse. Finally, numerous studies have interpreted the fact that college students say they did not use protection because they were drinking as evidence for a causal link between drinking and protective behaviors (Meilman, 1993; Wechsler et al., 1994). However, because people are notoriously poor at correctly identifying the causes of their behavior (Nisbett and Ross, 1980), such reports are better interpreted as expectancies or beliefs about alcohol's effects on risky sexual behavior, rather than as veridical accounts of alcohol effects on behavior. In short, the extant data reveal an inconsistent link between alcohol use and precautionary measures, a pattern that appears similar for men and women.

Co-occurrence of alcohol use and risky sexual behavior at the situational level

Although the above data indicate that people who drink are more likely to engage in indiscriminate sexual behaviors such as having multiple partners, they do not help us to adjudicate between competing explanations for the link between alcohol and risky sex. In fact, such data are equally compatible with both causal models. Determining whether alcohol use and risky sexual behaviors are reliably linked on a specific occasion, however, allows us to begin to ad- 
TABLE 2. Results from event-level studies examining the relationship between alcohol use and risky sexual behaviors

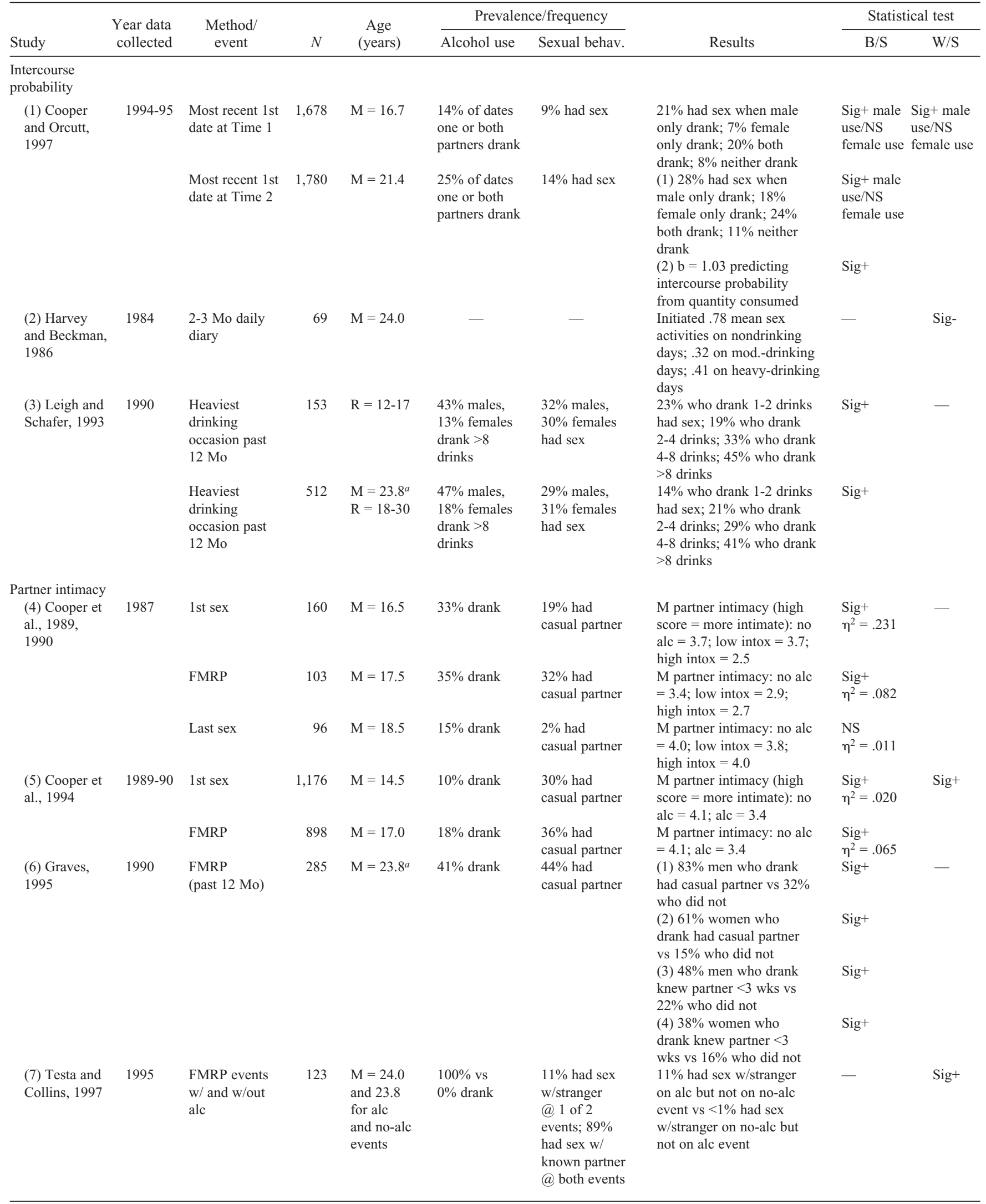


TABLE 2. Continued

\begin{tabular}{|c|c|c|c|c|c|c|c|c|c|}
\hline \multirow[b]{2}{*}{ Study } & \multirow{2}{*}{$\begin{array}{l}\text { Year data } \\
\text { collected }\end{array}$} & \multirow{2}{*}{$\begin{array}{c}\text { Method/ } \\
\text { event }\end{array}$} & \multirow[b]{2}{*}{$N$} & \multirow{2}{*}{$\begin{array}{l}\text { Age } \\
\text { (years) }\end{array}$} & \multicolumn{2}{|c|}{ Prevalence/frequency } & \multirow[b]{2}{*}{ Results } & \multicolumn{2}{|c|}{ Statistical test } \\
\hline & & & & & Alcohol use & Sexual behav. & & $\mathrm{B} / \mathrm{S}$ & $\mathrm{W} / \mathrm{S}$ \\
\hline \multirow{6}{*}{$\begin{array}{l}\text { Risk discussion } \\
\quad \text { (8) Cooper et } \\
\text { al., 1989, } \\
1990\end{array}$} & 1987 & 1 st sex & & Same & tudy 4 & $40 \%$ & M no. topics (of 3) & Sig + & - \\
\hline & & & & & & $\begin{array}{l}\text { discussed no } \\
\text { risk topics } \\
\text { before sex }\end{array}$ & $\begin{array}{l}\text { discussed: no alc }=.65 ; \\
\text { low intox }=.55 ; \text { high intox } \\
=.31\end{array}$ & $\eta^{2}=.076$ & \\
\hline & & FMRP & & Same & tudy 4 & $42 \%$ & M no. topics (of 3) & Sig+ & \\
\hline & & & & & & $\begin{array}{l}\text { discussed no } \\
\text { risk topics } \\
\text { before sex }\end{array}$ & $\begin{array}{l}\text { discussed: no alc }=.74 ; \\
\text { low intox }=.30 ; \text { high intox } \\
=.35\end{array}$ & $\eta^{2}=.157$ & \\
\hline & & Last sex & & Same & tudy $4-$ & $52 \%$ & M no. topics (of 3) & & \\
\hline & & & & & & $\begin{array}{l}\text { discussed no } \\
\text { risk topics } \\
\text { before sex }\end{array}$ & $\begin{array}{l}\text { discussed: no alc }=.48 ; \\
\text { low intox }=.34 ; \text { high intox } \\
=.62\end{array}$ & $\eta^{2}=.011$ & \\
\hline \multirow{4}{*}{$\begin{array}{l}\text { (9) Cooper et } \\
\text { al., } 1994\end{array}$} & $1989-90$ & 1 st sex & & Same & tudy 4 & & M no. topics (of 4) & Sig+ & Sig + \\
\hline & & & & & & $\begin{array}{l}\text { discussed no } \\
\text { risk topics }\end{array}$ & $\begin{array}{l}\text { discussed: } \text { no alc }=1.11 \\
\text { alc }=.82\end{array}$ & $\eta^{2}=.006$ & \\
\hline & & FMRP & & Same & tudy $5-$ & $\begin{array}{l}\text { before sex } \\
33 \%\end{array}$ & M no. topics (of 4) & Sig + & \\
\hline & & & & & & $\begin{array}{l}\text { discussed no } \\
\text { risk topics } \\
\text { before sex }\end{array}$ & $\begin{array}{l}\text { discussed: no alc }=1.36 \\
\text { alc }=.99\end{array}$ & $\eta^{2}=.012$ & \\
\hline $\begin{array}{l}\text { (10) Freimuth } \\
\text { et al., } 1992\end{array}$ & - & FMRP & 81 & $\mathrm{M}=20.7^{b}$ & $\begin{array}{l}42 \% \text { both } \\
\text { partners } \\
\text { drank or } \\
\text { used drugs }\end{array}$ & $\begin{array}{l}63 \% \text { initiated } \\
\text { discussion } \\
\text { re: } \mathrm{CU}\end{array}$ & $\begin{array}{l}\text { Alc/drug use predicted } \\
\text { lower likelihood of } \\
\text { initiating discussion in } \\
\text { discriminant analyses }\end{array}$ & Sig + & - \\
\hline $\begin{array}{l}(11) \text { Testa } \\
\text { and Collins, } \\
1997\end{array}$ & 1995 & $\begin{array}{l}\text { FMRP events } \\
\text { w/ and w/out } \\
\text { alc }\end{array}$ & & Same & tudy 7 & $\begin{array}{l}44 \% \\
\text { discussed no } \\
\text { risk topics } \\
\text { before either } \\
\text { occasion; } 15 \% \\
\text { discussed risk } \\
\text { before both }\end{array}$ & $\begin{array}{l}32 \% \text { discussed risk in no- } \\
\text { alc but not in the alc event } \\
\text { vs } 12 \% \text { discussed risk in } \\
\text { the alc but not in } \\
\text { the no-alc event }\end{array}$ & - & Sig + \\
\hline \multicolumn{10}{|l|}{$\begin{array}{l}\text { Condom/birth } \\
\text { control use }\end{array}$} \\
\hline \multirow{8}{*}{$\begin{array}{l}\text { control use } \\
\text { (12) Boldero } \\
\text { et al., } 1992 \\
\text { (13) Cooper } \\
\text { et al., 1989, } \\
1990\end{array}$} & - & Last sex & 144 & $\mathrm{M}=18.7$ & - & $65 \%$ used C & $\begin{array}{l}\mathrm{B}=-.29 \text { predicting } \mathrm{CU} \\
\text { from alc }\end{array}$ & NS & - \\
\hline & 1987 & 1 st sex & & Same & tudy 4 & $\begin{array}{l}43 \% \text { used } C \\
52 \% \text { used } B C\end{array}$ & $\begin{array}{l}\text { (1) } \% \text { used C: no alc }=44 ; \\
\text { low intox }=54 \text {; high intox } \\
=31\end{array}$ & $\begin{array}{l}\text { NS } \\
\eta^{2}=.019\end{array}$ & - \\
\hline & & & & & & & $\begin{array}{l}\text { (2) } \mathrm{M} \mathrm{BC} \text { effectiveness: no } \\
\text { alc }=2.2 ; \text { low intox }=2.2 ; \\
\text { high intox }=2.0\end{array}$ & $\begin{array}{l}\text { NS } \\
\eta^{2}=.007\end{array}$ & \\
\hline & & FMRP & & Same & tudy 4 & $\begin{array}{l}57 \% \text { used C; } \\
67 \% \text { used BC }\end{array}$ & $\begin{array}{l}\text { (1) } \% \text { used C: no alc }=66 ; \\
\text { low intox }=40 \text {; high intox } \\
=44\end{array}$ & $\begin{array}{l}\text { Marg+ } \\
\eta^{2}=.049\end{array}$ & \\
\hline & & & & & & & $\begin{array}{l}\text { (2) } \mathrm{M} \mathrm{BC} \text { effectiveness: no } \\
\text { alc }=2.7 ; \text { low intox }=2.6 ; \\
\text { high intox }=2.3\end{array}$ & $\begin{array}{l}\text { NS } \\
\eta^{2}=.026\end{array}$ & \\
\hline & & Last sex & & Same & tudy 4 & $53 \%$ used C; & (1) $\%$ used C: no alc $=54$ & & \\
\hline & & & & & & $79 \%$ used $\mathrm{BC}$ & & $\eta^{2}=.010$ & \\
\hline & & & & & & & $\begin{array}{l}\text { (2) M BC effectiveness: no } \\
\text { alc }=2.9 ; \text { low intox }=2.8 ; \\
\text { high intox }=3.5\end{array}$ & $\begin{array}{l}\text { NS } \\
\eta^{2}=.034\end{array}$ & \\
\hline \multirow[t]{2}{*}{$\begin{array}{l}\text { (14) Cooper } \\
\text { et al., } 1994\end{array}$} & $1989-90$ & 1 st sex & & Same & tudy $5-$ & $46 \%$ used C & $\begin{array}{l}44 \% \text { no alc used C vs } 33 \% \\
\text { w/alc }\end{array}$ & $\begin{array}{l}\text { Sig }+ \\
\eta^{2}=.004\end{array}$ & NS \\
\hline & & FMRP & & Same & tudy $5-$ & $46 \%$ used C & $43 \%$ no alc used C vs $44 \%$ & & \\
\hline $\begin{array}{l}\text { (15) Dermen } \\
\text { and Cooper, } \\
\text { Study } 1 \text {, } \\
2000\end{array}$ & 1993 & FMRP & 308 & $\mathrm{M}=18.8$ & $29 \%$ drank & $72 \%$ used C & $\begin{array}{l}\text { W/alc } \\
\beta=-.121 \text { predicting } C U \\
\text { from alc use (coded } 0= \\
\text { none to } 2=\geq 4 \text { drinks) }\end{array}$ & $\begin{array}{l}\eta^{2}=.000 \\
\text { NS }\end{array}$ & - \\
\hline $\begin{array}{l}\text { (16) Dermen } \\
\text { and Cooper, } \\
\text { Study } 2 \text {, } \\
2000\end{array}$ & 1994-95 & 1 st sex & 465 & $M=16.7$ & $11 \%$ drank & $68 \%$ used C & $\begin{array}{l}\beta=-.205 \text { predicting } \mathrm{CU} \\
\text { from alc use (coded as } \\
\text { in study } 15 \text { ) }\end{array}$ & NS & - \\
\hline
\end{tabular}


Table 2. Continued

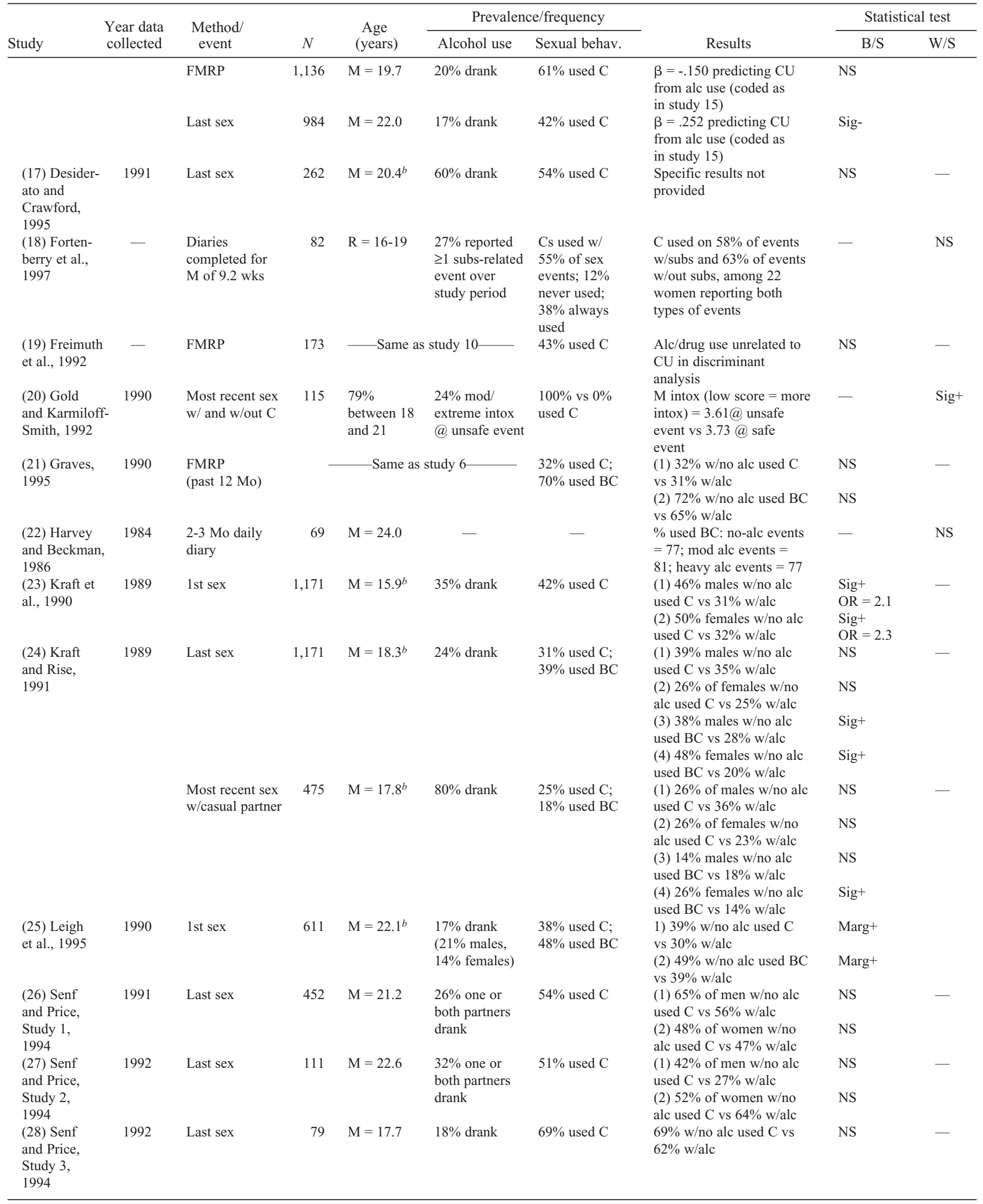


TABLE 2. Continued

\begin{tabular}{|c|c|c|c|c|c|c|c|c|c|}
\hline \multirow[b]{2}{*}{ Study } & \multirow{2}{*}{$\begin{array}{l}\text { Year data } \\
\text { collected }\end{array}$} & \multirow{2}{*}{$\begin{array}{l}\text { Method/ } \\
\text { event }\end{array}$} & \multirow[b]{2}{*}{$N$} & \multirow{2}{*}{$\begin{array}{l}\text { Age } \\
\text { (years) }\end{array}$} & \multicolumn{2}{|c|}{ Prevalence/frequency } & \multirow[b]{2}{*}{ Results } & \multicolumn{2}{|c|}{ Statistical test } \\
\hline & & & & & Alcohol use & Sexual behav. & & $\mathrm{B} / \mathrm{S}$ & $\mathrm{W} / \mathrm{S}$ \\
\hline $\begin{array}{l}\text { (29) Testa } \\
\text { and Collins, } \\
1997\end{array}$ & 1995 & $\begin{array}{l}\text { FMRP events } \\
\text { w/ and w/out } \\
\text { alcohol }\end{array}$ & & Same a & tudy $7-$ & $\begin{array}{l}51 \% \text { used C } \\
\text { both events; } \\
89 \% \text { used } \\
\text { protection } \\
\text { both events; } \\
4 \% \text { used } \\
\text { nothing @ } \\
\text { either } \\
\text { event }\end{array}$ & $\begin{array}{l}\text { (1) } 16 \% \text { used C in no-alc } \\
\text { but not in alc event vs } \\
19 \% \text { used C in alc but } \\
\text { not in no-alc event } \\
\text { (2) M no. drinks: } \mathrm{C} \text { users } \\
=6.26 \text {; nonusers }=6.32\end{array}$ & NS & NS \\
\hline $\begin{array}{l}\text { (30) Traeen } \\
\text { and Kvalem, } \\
1996\end{array}$ & 1990 & Last sex & 385 & $\mathrm{M}=17.4^{b}$ & $24 \%$ drank & $72 \%$ used $\mathrm{BC}$ & $\begin{array}{l}48 \% \text { w/no alc used BC } \\
\text { vs } 23 \% \text { w/alc }\end{array}$ & Sig+ & - \\
\hline
\end{tabular}

Notes: $N=$ sample size; $\mathrm{B} / \mathrm{S}=$ between subjects; $\mathrm{W} / \mathrm{S}=$ within subjects; $\mathrm{M}=$ mean; $\mathrm{NS}=$ not significant; $\mathrm{Mo}=$ month; dash $(-)=$ not reported or not applicable; $\mathrm{R}=$ range; FMRP = first sex with most recent or current partner; $\mathrm{BC}=$ birth control; $\mathrm{C}=$ condom; $\mathrm{CU}=$ condom use; $\mathrm{OR}=$ odds ratio. Significant positive results ( $\mathrm{Sig}+$ ) indicate results that support a link between alcohol use and increased risky behavior, regardless of the direction in which behavior was coded in the study. Significant negative results (Sig-) indicate results that showed a link between alcohol use and decreased risky behavior. Results designated as significant were significant at $p<.05$ by the relevant statistical test; marginal results (Marg+) were significant at $p<.10$.

${ }^{a}$ Age at time of event estimated by subtracting 6 months from age at time of the interview. This assumes that events occurred on average 6 months, about half-way, through the 1-year reporting window. ${ }^{b}$ Age estimated from categorical data for the event. For Leigh et al. (study 25 ), $49 \%$ of the sample had sex more than 5 years ago. Hence, age at the time of interview (the only age given) substantially overestimates average age at first intercourse. Accordingly, age at first intercourse was adjusted downward in the analyses of sample age (reported in the text), although unadjusted age is reported here.

judicate between the two models because covariation on a given occasion is a necessary but not sufficient condition for attributing risky sexual behaviors to acute alcohol intoxication.

Evidence from multiple studies shows that college students regularly combine drinking with sex on specific occasions (see Table 1). As previously argued, however, some overlap would be expected by chance alone. Thus two strategies have been used to test whether drinking and risky sex reliably covary at the situation level: (1) between-persons tests in which the behavior of people who drink on a given occasion are compared with those who do not drink to determine if drinkers exhibited riskier behaviors on that occasion and (2) within-persons tests in which the behaviors of individuals are compared on drinking and nondrinking occasions to determine whether riskier behaviors were exhibited on drinking occasions. Although most studies have used between-persons comparisons, such comparisons cannot rule out the possibility that stable individual differences cause people both to drink and take risks on a given occasion (Cooper et al., 1990). In contrast, because an individual's personality or lifestyle is unlikely to change from event to event, within-persons comparisons are less vulnerable to this alternative explanation and thus enable stronger attributions to alcohol use as the causal agent.

Using both analytic strategies, three key questions have been addressed at the situational level of analysis: (1) Does drinking in potentially sexual situations alter the probability that intercourse will occur? Once intercourse occurs, does drinking beforehand (2) increase indiscriminate risky sexual behaviors, or (3) decrease protective behaviors? Stud- ies addressing each of these questions are summarized in Table 2 and are reviewed next.

Alcohol use and intercourse probability. Using data from three independent samples, a total of seven betweenpersons and three within-persons tests of the link between alcohol and intercourse probability have been conducted. Across these studies, five of the seven between-persons tests were significant and positive, and two were nonsignificant. The within-persons tests yielded one positive, one negative and one null finding. Despite the pattern of inconsistent results, a closer examination of these studies suggests a potentially heuristic integration.

In the first study to provide a within-persons test (Harvey and Beckman, 1986), 69 university women kept daily logs of their alcohol use and sexual behavior. Contrary to the women's self-professed beliefs about alcohol's capacity to increase sexual desire, they were actually less likely to initiate intercourse after a drinking than after an alcohol-free period. In the second study to provide a within-persons test (Cooper and Orcutt, 1997), alcohol use and sexual behavior were measured on two different first-date occasions, separated by 4.5 years. Results showed that intercourse probability across the two dating occasions covaried with male, but not with female, partner use. (Supplemental analyses indicated that the male partner effect was not due to coercion.)

Together, these studies raise the possibility that alcohol can either inhibit or promote sexual contact, depending on characteristics of the individual and the relationship. Given that reliable effects were found only among men in the Cooper and Orcutt (1997) study, the use of an all-female 
sample in Harvey and Beckman's (1986) study could account for the discrepant result. Perhaps more important, only individuals in stable relationships were included in Harvey and Beckman's study, whereas Cooper and Orcutt examined first-date situations, which are likely to involve new or casual partners. According to alcohol myopia theory, alcohol effects on intercourse probability should be greatest in situations where both strong instigating (e.g., sexual arousal) and strong inhibiting (e.g., fear of disease, anticipation of guilt or regret) cues control the behavior. Although instigating cues might be similar when having sex with a new versus established sex partner, inhibiting cues are unlikely to be. Consistent with this analysis, Cooper and Orcutt (1997) found that intercourse probability increased only among men who both drank and were highly conflicted (i.e., perceived both strong benefits and strong costs) about having sex on the date.

This finding may also help explain why the effect was restricted to men. For women, the perceived costs of having sex (e.g., loss of reputation) substantially outweighed perceived benefits, thus creating little conflict. In contrast, costs and benefits were nearly equal in strength among men, leading to greater conflict about whether to have sex. In short, these data suggest that alcohol has the potential to disinhibit sexual behavior among both men and women, but that whether it will depends on what the behavior means to the individual in the situation.

Alcohol use and indiscriminate sexual behaviors. Two different indicators of indiscriminate sexual behavior have been examined: having sex with a casual or hardly known partner and failure to discuss risk topics prior to intercourse. Using data from four independent samples, a total of nine between-persons and two within-persons tests of the link between drinking and partner intimacy have been conducted. Eight of the nine between-persons tests and both of the within-persons tests were significant, with all effects indicating a positive link between drinking and having a more casual partner. Using data from four independent samples, a total of six between-persons and two within-persons tests of the link between alcohol and risk discussion were also conducted. Five of the six between-persons and both of the within-persons tests were significant, with all effects showing decreased risk discussion among individuals who drank prior to intercourse. In the studies that reported results separately for men and women (Graves, 1995) or tested gender interactions (Cooper et al., 1994), no evidence for gender differences in either outcome was found.

It is interesting to note that the two null results (for partner intimacy and discussion) were obtained in the same study for the same event-last intercourse (Cooper et al., 1989, 1990). Because this event included only sexual experiences with an established sexual partner, few respondents considered their partner casual (see Study 4, Table 2); thus simple restriction of range may account for the null find- ing. In addition, it seems likely that individuals who intended ever to discuss risk topics would have done so by their last intercourse experience, which occurred in the Cooper et al. $(1989,1990)$ study about 1 year after first intercourse with that partner. Although an individual might feel conflicted about bringing up risk-related topics with a new sex partner, it is unlikely that he or she would continue to feel conflicted a year later with the same partner. A related possibility is that these behaviors index qualitatively different phenomena in the early versus later stages of a relationship. In an established relationship, for example, perceiving your partner as less intimate may indicate a stagnant or troubled relationship, whereas failure to discuss risk topics may indicate intimacy avoidance or social skill deficits on the part of one or both partners. Thus, although these behaviors may validly index risk in the early stages of a relationship, their meaning - and hence their relationship to alcohol use - may shift over time.

Alcohol use and protective behaviors. A total of 25 between-persons and 4 within-persons tests of the link between alcohol and condom use have been conducted using data from 15 independent samples. Of these, only five between-persons tests (two at $p<.10$ ) and one within-persons test showed a significant inverse relationship between drinking and condom use. Of the remaining 23 betweenpersons tests, one revealed significantly more condom use among those who drank (Dermen and Cooper, 2000), whereas 22 were nonsignificant. Ten between-persons and one within-persons tests of the link between alcohol and birth control use were conducted using data from five independent samples. Of these, five between-persons tests showed a significant or marginally significant relationship between drinking and decreased birth control use, whereas the remaining six tests were nonsignificant.

Comparison of sexual events for which significant decreases in condom or birth control use were found with events that yielded null results pointed to several factors that might explain the variability in results. First, sample size was significantly positively associated with obtaining an alcohol effect (mean [SD] size $=504$ [303.6] versus 318 [302.3], $t=1.7, p<.10$, for studies finding significant versus nonsignificant effects). Second, a preponderance of significant effects were found for lifetime first intercourse: 5 of 8 such tests were significant, compared with 2 of 13 tests for first time with most recent or current partner and 3 of 15 tests for last intercourse $\left(\mathrm{x}^{2}=6.3,2 \mathrm{df}, p<.05\right)$. Third, participants were significantly younger at the time of sexual events for which an inverse effect of alcohol use on protective behaviors was found (mean $=17.4$ [1.6] years) compared with events finding no such effect (mean $=19.6$ [2.5] years; $t=3.4, p<.01$ ). Fourth, significant alcohol effects were more likely for events that occurred longer ago; $r=-.37(p<.05)$ between year of data collection and finding a significant inverse effect. Indeed, all significant 
effects were found for events that occurred during or prior to 1990. Because event (first intercourse versus other events), age at time of intercourse and year in which the event occurred were interrelated ( $r$ 's ranged from .38 to $.54, p$ 's $<.05)$, a logistic regression analysis was conducted to determine whether the three event characteristics independently predicted the likelihood of obtaining a significant alcohol effect. Results showed that although the set of event characteristics was significant $\left(\mathrm{x}^{2}=12.2,3 \mathrm{df}, p\right.$ $<.01$ ), none of the characteristics individually predicted outcome. This suggests that effects among these factors can- not be adequately parsed. Finally, other event characteristics (including gender and racial composition of the samples, whether the sample was a college or noncollege sample, whether a random or convenience sample was used, whether condom or birth control use served as the dependent measure and whether a between-persons or within-persons test was conducted) were not related to obtaining a significant effect. In short, these data suggest that the link between drinking and failure to take protective actions is likely circumscribed by historical context, as well as by developmental stage and chronological age.

\section{Conclusions and Recommendations for Research and Prevention}

\section{Summary and conclusions}

The above research supports a number of conclusions about the link between alcohol use and risky sexual behavior among college students and more generally among adolescents and young adults. First, existing research indicates that alcohol use and certain types of sexual behavior covary. Not only does the likelihood that an individual has ever drunk alcohol predict the likelihood he or she has ever had sex, but level of alcohol involvement also predicts level of sexual involvement. Equally strong evidence suggests that drinking in a potentially sexual situation (e.g., on a date) is associated with an increased probability of intercourse on that occasion and that drinking prior to intercourse is associated with risky partner choice as well as with decreased risk discussion on that occasion. Each of these relationships has been observed using within-persons designs, thus ruling out the possibility that strictly between-person differences can account for the data. These effects, however, may be qualified by relationship status and, in the case of intercourse probability, perhaps by gender as well.

In contrast to the relatively clear-cut results linking alcohol use to increased participation in indiscriminate sexual behaviors (especially having casual sex), studies examining the link between drinking proximal to intercourse and decreased protective behaviors (i.e., condom and birth control use) reveal a weaker link. Indeed, the overwhelming majority of studies, whether examining global or situation- specific associations, found no effect whatsoever. The primary exceptions to this pattern were found for younger, sexually inexperienced adolescents and for sexual events occurring during or prior to 1990 . Thus these data suggest that the link between alcohol use and protective behaviors is both developmentally and historically limited.

Gender and race differences in the relationship between drinking and risky sexual behaviors are equivocal. Although gender differences have been reported (e.g., Cooper and Orcutt, 1997), they have not been consistently observed across different behaviors or across different studies investigating the same behavior (e.g., Dermen and Cooper, 2000). Evidence on race differences is inconclusive because of the small number of studies that have included black youth and because few black adolescents and young adults drink in sexual situations (Cooper et al., 1994; Leigh et al., 1995).

Despite the complexity of these findings, the overall pattern of data can be parsimoniously interpreted within the framework of Steele and Josephs' (1990) alcohol myopia theory. As previously described, alcohol is hypothesized to affect behavior only when that behavior is controlled by competing cues (one set favoring action and one inhibiting action) of nearly equal strength. Theoretically, then whether alcohol affects behavior in a given situation should be determined by the relative strength and content of the dominant versus peripheral cues governing behavior in that situation. For example, when dominant cues favor inaction and peripheral cues favor action, alcohol may lead to behavioral inhibition as opposed to disinhibition. Thus, to the extent that the nature and strength of competing cues (or costs and benefits) related to having sex with a particular partner or to engaging in any specific sexual behavior vary across the life span of the relationship, alcohol's effects on those behaviors should also vary across time (or stage) within that relationship. Likewise, because the nature and strength of these cues are thought to follow a distinctive course for men and women at different stages of relationship development (McCabe and Collins, 1984), the nature of alcohol effects on behavior may differ for men and women at some, although not necessarily all, stages of a relationship (cf., Cooper and Orcutt, 1997). Indeed, it is likely that any classificatory variable (e.g., age, historical period, race) that can be shown to moderate alcohol effects on sexual behavior is in fact a proxy for mean or grouplevel differences in the type and relative strength of competing cues that control the behavior in question. This line of reasoning therefore suggests that direct assessment of the competing cues and associated levels of conflict about engaging in the behavior should yield more precise specification of the conditions under which alcohol leads to increased or perhaps even decreased sexual risk taking.

At the same time, beliefs about the effects of alcohol on risky sexual behavior also appear to play an important role. Indeed, overwhelming evidence indicates that people be- 
lieve that alcohol causally promotes risky sexual behaviors. These beliefs, in turn, have been shown to promote drinking in sexual or potentially sexual situations (Dermen and Cooper, 1994; Leigh, 1990) and (in the absence of actual alcohol) to elicit disinhibited sexual behavior consistent with individually held expectancies in laboratory studies (George et al., 2000). Evidence that individually held expectancies moderate alcohol's effects on risky sexual behavior, however, is less consistent (see Dermen and Cooper, 2000; Dermen et al., 1998; Leigh, 1990). Although such inconsistencies could reflect well-known statistical difficulties associated with detecting interactions in correlational data (McClelland and Judd, 1993) or difficulties inherent in predicting complex behaviors in specific situations (Epstein, 1983), they might also reflect a need for greater refinement in our theories and methods for testing these theories. One possibility is that the strength and relevance of an individual's beliefs about how alcohol affects sexual behavior vary across situations and that these variations are partly determined by the specific meaning that engaging in the behavior has for the individual on that occasion. Consider, for example, an individual who experiences conflict about having sex on two different occasions. On the first occasion, conflict arises because he is aroused, but fears that having sex will lead to undesired expectations on the part of his partner with whom he has no intention of pursuing a relationship. On the second occasion, the individual is again aroused by the prospect of having intercourse, but this time experiences conflict because he fears that having sex might damage a relationship that he hopes will develop into a more serious one. Thus the belief that alcohol leads to excesses in behavior might provide a plausible post hoc excuse for having sex in the first situation, but would be irrelevant in the latter situation to concerns about damaging an incipient relationship. In short, a complex match may be required between the content of one's beliefs about alcohol effects on behavior and the perceived costs and benefits of engaging in that behavior on a given occasion. Such possibilities underscore the potentially crucial role that an individual's idiosyncratic construction of his or her behavioral options in a given situation play, as well as the need to integrate expectancy and conflict inhibition models of alcohol effects on behavior.

One question that remains unanswered, however, is why drinking should be more reliably linked to indiscriminate behaviors than to protective behaviors. At least two interrelated explanations may account for this pattern of findings. First, alcohol effects on protective behaviors may be entirely indirectly mediated by its effects on indiscriminate behaviors (Cooper et al., 1999). According to this possibility, drinking directly affects the likelihood of having a casual partner and of discussing risk-relevant topics, and these behaviors in turn affect the probability of taking protective actions. Differences in the magnitude of the relationships, and hence the ease with which they can be detected, would follow as a consequence of one being a direct effect and the other being an indirect one. The second possibility is a subset of the first one in that it invokes a specific type of intervening variable model in which the direct and indirect (or spurious) effects are opposite in sign. Specifically, Cooper and Orcutt (2000) have shown that this circumstance (known as suppression) may arise because people are more likely both to drink and to use a condom if they have sex with a casual than a serious partner. It therefore follows that the overall association between drinking and condom use includes this pathway of positive influence, which would attenuate, or possibly mask altogether, any adverse direct effects of drinking on condom use. To the extent that this analysis is accurate, the total effect of alcohol use on condom use would necessarily be smaller than its direct effect, after controlling for partner intimacy. Consistent with this interpretation, we found that the total effect of alcohol use on condom use was -.04 and not significant, but that its direct effect after controlling for partner intimacy ratings was -.17 and significant. Findings reported by Gold et al. (1992), who reported the only significant within-persons effect for condom use among the previously reviewed studies, lend further credence to this interpretation. The key difference between their study and the remaining studies was that they controlled for partner intimacy by limiting their analyses to the subset of individuals who had equally intimate partners across the two occasions. To summarize, these data suggest that the overall magnitude of the relationship between alcohol use and protective behaviors is small because these behaviors are part of a larger multivariate network of relationships in which the two variables are only indirectly linked, or in which any direct relationship they have is obscured by a countervailing process.

Finally, because of pragmatic concerns with the potentially devastating consequences of acute alcohol intoxication, the present review has focused to a substantial degree on this particular explanation for the link between drinking and risky sex. This focus should not be interpreted, however, as a statement about the greater plausibility or importance of this causal model relative to other possible models. In fact, given the highly conditional nature of the link between alcohol and risky sex at the level of the situation, it seems unlikely that acute alcohol effects alone could adequately account for the robust associations observed between these behaviors at the global level. Moreover, even though within-persons procedures show that the same person is more likely to engage in risky sex on drinking than on nondrinking occasions, these data do not unambiguously point toward a causal effect of alcohol on risky sexual behavior. Indeed, they are equally compatible with both reverse causal and third-variable situational explanations as well (Cooper, 1992; Cooper et al., 1994). In short, the extant data indicate that no single causal model can adequately 
account for the relationship between alcohol use and risky sexual behavior and rather that a range of plausible models must be embraced. The present review focused on two such models that are both consistent with the evidence on covariation and plausible in terms of what is known about alcohol use, risky sex and their interrelationship. Together these considerations suggest that it is time to move beyond the question of which model better accounts for the observed covariation of these two behaviors and to begin instead to address the question of under what circumstances, or for which individuals or subgroups, different causal processes operate.

\section{Recommendations for future research and intervention efforts}

Based on the above review, a number of recommendations can be offered for future research and intervention efforts.

Study design. The vast majority of research on this topic has been cross-sectional and included only global assessments of behavior. Although such studies (assuming known sampling parameters) can provide useful data on the prevalence and magnitude of the contemporaneous association of these behaviors, they are not optimal for illuminating processes by which these behaviors are linked. The strongest tests of hypotheses concerning acute alcohol effects, for example, require short-term, repeated measures in which multiple sexual or potentially sexual events are examined. Diary studies, although they present formidable methodological challenges (Reis and Gable, 2000), nevertheless represent the most rigorous, ecologically valid approach currently available for testing key premises of acute effect models. Compared with the more widely used critical event approach in which alcohol and sexual behaviors are described for some past occasion such as first intercourse, diary studies can collect data virtually online. The resulting proximity in time of the self-report to the actual experience greatly reduces, if not eliminates, retrospective recall bias, thus leading to substantially more accurate reporting.

Critical event methodology will remain an important adjunct to diary studies, however, in part because of its greater flexibility and ease of use. For this reason, it will be important to develop a better understanding of the limits of the critical event approach, as well as to identify ways to enhance its validity. Regardless of whether a critical event or diary method is used, data should be collected for at least two events (that vary on alcohol consumption) and analyzed using within-persons procedures. Such procedures offer one of the only feasible ways to rule out stable individual differences as an alternative interpretation of any observed linked between drinking and risky sexual behavior.

Although issues of external validity are paramount, controlled experimentation can also play an important role.
Small-scale laboratory analog studies designed to test highly focused hypotheses about underlying mechanisms (cf., Fromme et al., 1999) can explore subtle aspects of causal process that would otherwise be difficult to isolate. Carefully designed field experiments (cf., MacDonald et al., 1996) and intervention studies (cf., Dermen and Thomas, 2000) have been underutilized to date, yet hold substantial promise for exploring causal processes in an externally valid manner. To be maximally informative, however, such studies should be theoretically informed and focus on testing relevant mediation and moderation hypotheses.

Finally, future studies examining the link between drinking and risky sexual behavior should include data from both partners. Because sexual behavior is played out in intimate, interpersonal contexts and requires mutual action, gaining the perspective of only one partner is inherently limited. This may be especially true in the present arena where alcohol effects on risky sexual behaviors appear to depend heavily on individual meanings ascribed (presumably by both partners) to the focal behavior.

Measurement issues. The majority of studies to date have focused on global assessments of alcohol use and risky sexual behavior and ignored theoretical variables that might mediate or moderate the links between them. The present review suggests that continued progress in this area depends on more refined assessments of all three sets of variables.

First, assessment of alcohol use can be improved in at least two important ways. Unlike most studies where drinking is assessed for the participant only, a separate measure of partner alcohol use should be obtained. Given the unique effects of male and female partner use previously discussed (Cooper and Orcutt, 1997), this simple step seems crucial. In addition, future researchers should attempt to measure situation-specific expectancies (Dermen and Cooper, 1994) or reasons for drinking (Cooper, 1994) on a given occasion. Only by directly assessing what the individual expects to happen as a result of drinking in a given situation (expectancies), or hopes to gain by drinking in that situation (motives), can we begin to unravel the differential effects of drinking on risky sexual behavior, both across persons and within persons across situations.

Second, several recommendations for improved assessment of risky sexual behaviors also can be offered. Direct assessment of conflict about engaging in the focal behavior appears critical. Toward this end, Cooper and colleagues (Cooper and Orcutt, 1997; Dermen and Cooper, 2000) developed a simple but promising approach in which individuals rate the degree to which they felt conflicted, uncertain or ambivalent about engaging in a given behavior on a specific occasion (e.g., using a condom at last sex). As previously discussed, conflict ratings were found to moderate alcohol effects on intercourse probability and condom use in theoretically consistent manners. Ratings of costs and benefits associated with these behaviors also were 
shown to discriminate among qualitatively different forms of conflict - namely, conflict in which costs outweigh benefits versus benefits outweigh costs. Our research suggests that this distinction provides leverage for discriminating between situations where drinking leads to behavioral inhibition versus disinhibition (Cooper and Orcutt, 1997) and should therefore be included whenever possible.

Future assessments of sexual risk taking should move beyond their near-exclusive focus on condom use. This approach, while tapping the most essential element from an AIDS prevention perspective, leaves unmined important aspects of the sexual encounter that in and of themselves pose risk or help to define risk from the individual's perspective. For example, an individual may not construe failure to use a condom as risky or may not experience conflict about nonuse if other birth control is used. Also, failure to use protection cannot be construed as risky if one is intentionally trying to conceive. Thus assessing pregnancy intentions as well as other forms of birth control use should provide crucial insights into the individual's psychological experience of the situation.

Although rarely included in prior research, more careful attention to risk discussion as an outcome appears warranted. A recent meta-analysis (Sheeran et al., 1999) found that communication between partners about condom use was the single strongest predictor of condom use $(r=.46)$ among 56 different variables examined. At the same time, asking a partner about his or her past sexual experiences may inadvertently lead to increased risk taking because people sometimes intentionally misrepresent their past sexual experiences to have sex (Cochran and Mays, 1990). These considerations suggest the need for separate assessments of discussion of protective behaviors and discussion of other risk topics.

The heterogeneity of alcohol effects on risky behaviors observed in the present review underscores the need to assess multiple risk behaviors as well as to develop differentiated hypotheses regarding links between drinking and individual risk behaviors. Indeed, the fact that risk behaviors themselves are related to one another in complex ways suggests the need to move toward multivariate models in which alcohol use is embedded within a network of interrelated risk behaviors (cf., Cooper and Orcutt, 2000).

Finally, greater attention needs to be paid to the relationship context, even in studies where data are collected from only one partner. In past research, participants have typically been asked to describe the nature of the relationship with their partner at the time of intercourse, for example, on a scale ranging from someone they just met to a fiancé or spouse. Alternatively, participants may be asked how long they have known, dated or been with their partner or to rate how well they know their partner. Although such assessments appear to sort individuals reliably along a crude intimacy continuum, they fail to capture the rich psy- chological terrain that characterizes most sexual relationships. Thus, to the extent possible, measures aimed at assessing a broader range of relationship dimensions and functioning (e.g., interdependency, power, passion, trust, commitment) should be included. Of course, such assessments assume that a relationship of at least some duration exists between the two partners. When this is not the case, assessing the individual's goals or intentions vis-à-vis the partner or the specific sexual encounter may adequately capture his or her orientation to the relationship.

Despite the potential of data such as these to illuminate crucial aspects of the link between drinking and risky sexual behavior, they are not without their limitations. Retrospective reports of perceived aspects of events or relationships, particularly when collected substantially after the fact, are highly subjective and vulnerable to distortion. However, by comparing retrospective self-reports of experiences obtained from both partners, or by comparing retrospective reports to diary data, we may begin to identify aspects of sexual experience that are more (and less) reliably indexed by retrospective self-reports, as well as variations in assessment procedures that enhance the accuracy of such reports.

Implications for intervention. The present review has a number of important implications for intervention. First, existing evidence supports the plausibility of multiple causal models. The existence of multiple models underscores the need for caution in interpreting evidence of covariation between these behaviors as prima facie evidence for a causal link. It also highlights the need for diverse methodological approaches for exploring alternative models and raises the possibility that different intervention strategies will be optimally effective among individuals or subgroups for whom different causal processes predominate. Among people who chronically drink and engage in risky behaviors, for example, the relationship between alcohol use and sexual risk taking may primarily arise from an underlying common cause or causes. For such individuals, more universal change strategies targeting the hypothesized common cause (e.g., a risk-seeking propensity) should be maximally efficacious. In contrast, carefully designed intervention studies aimed at reducing drinking in settings where drinking and potential partners co-occur (e.g., in college bars) could provide important insights into the nature of situational processes that give rise to the link between drinking and risky sex, as well as lower sexual risks associated with drinking for those individuals who are vulnerable to acute intoxication effects, situational influences or both.

In short, future intervention studies should attempt to match individuals to different intervention approaches on the basis of theoretical considerations about plausible underlying causes. A series of well-controlled, theoretically informed trials would not only shed light on the nature of multiple causal processes that underpin the link between alcohol and risky sex, but also provide a set of effective 
intervention strategies that could be targeted for use with different audiences. Although the main findings of Project MATCH (Project MATCH Research Group, 1997, 1998) did not support the notion of patient-treatment matching, it is possible that the basis for matching to treatments in that study was not sufficiently sensitive to variations in underlying causal structures. Accordingly, careful efforts to identify reliable markers of different underlying process models will be needed to maximize the likelihood of success of such an endeavor.

In sum, the relationship between alcohol use and risky sexual behavior appears to be both complex and highly circumscribed. Nevertheless, the fact that this relationship appears most potent in the context of new or casual dating and sexual relationships heightens the importance of this issue among college students who, on average, have more than eight new sex partners over their 4 years in college (see Table 1). Because of limited drinking and sexual experience typical of most students prior to college, and the unprecedented freedoms to experiment that college environments typically provide, college students - more so than most other groups - may combine drinking and sex in ways that jeopardize their mental and physical well-being.

\section{Acknowledgments}

Special thanks are extended to Sharon Wilsnack, Patrick Johnson, Kenneth Sher, Vivian Faden and the remaining members of the Panel on College-Age Drinking for their guidance on this project. Thanks also to Howard Tennen for thoughtful comments on an earlier version of this article.

\section{References}

Alan Guttmacher Institute. Sex and America's Teenagers, New York: Alan Guttmacher Institute, 1994.

BAER, J.S. Effects of college residence on perceived norms for alcohol consumption: An examination of the first year in college. Psychol. Addict. Behav. 8: 43-50, 1994.

Baldwin, J.D., Whiteley, S. AND Baldwin, J.I. The effect of ethnic group on sexual activities related to contraception and STDs. J. Sex Res. 29: 189-205, 1992

Boldero, J., Moore, S. and Rosenthal, D. Intention, context, and safe sex: Australian adolescents' responses to AIDS. J. Appl. Social Psychol. 22: 1374-1396, 1992.

Brooks-Gunn, J. And Paikoff, R. Sexuality and developmental transitions during adolescence. In: Schulenberg, J. And MagGS, J.L. (Eds.) Health Risks and Developmental Transitions During Adolescence, New York: Cambridge Univ. Press, 1997, pp. 190-219.

Caspi, A., Begg, D., Dickson, N., Harrington, H., Langley, J., Moffitt, T.E. AND SiLva, P.A. Personality differences predict health-risk behaviors in young adulthood: Evidence from a longitudinal study. J. Pers. Social Behav. 73: 1052-1063, 1997.

Cochran, S.D. and Mays, V.M. Sex, lies, and HIV. New Eng. J. Med. 322: 774-775, 1990.

CoOper, M.L. Alcohol and increased behavioral risk for AIDS. Alcohol Hlth Res. World 16: 64-72, 1992.

CoOPer, M.L. Motivations for alcohol use among adolescents: Development and validation of a four-factor model. Psychol. Assess. 6: 117128,1994
Cooper, M.L., Agocha, V.B. And Albino, A. Mediation of alcohol effects on condom use (abstract). Alcsm Clin. Exp. Res. 23: 120A, 1999.

Cooper, M.L., Agocha, V.B. and Sheldon, M.S. A motivational perspective on risky behaviors: The role of personality and affect regulatory process. J. Pers. 68: 1059-1088, 2000.

Cooper, M.L. And Orcutt, H.K. Drinking and sexual experience on first dates among adolescents. J. Abnorm. Psychol. 106: 191-202, 1997.

Cooper, M.L. AND Orcutt, H.K. Alcohol use, condom use, and partner type among heterosexual adolescents and young adults. J. Stud. Alcohol 61: 413-419, 2000.

Cooper, M.L., Peirce, R.S. and Huselid, R.F. Substance use and sexual risk taking among black adolescents and white adolescents. Hlth Psychol. 13: 251-262, 1994.

Cooper, M.L., Shapiro, C.M. And Powers, A.M. Motivations for sex and sexual behavior among adolescents and young adults: A functional perspective. J. Pers. Social Psychol. 75: 1528-1558, 1998.

Cooper, M.L., Skinner, J.B. and George, W.H. Alcohol use and sexual risk-taking among adolescents: Methodological approaches for addressing causal issues. In: Seminara, D., Watson, R.R. and Pawlowski, A. (Eds.) Alcohol, Immunomodulation, and AIDS, New York: Alan R. Liss, 1990, pp. 11-19.

Cooper, M.L., Skinner, J.B., George, W.H. and Brunner, L.J. Adolescent alcohol use and high risk sexual behaviors. Paper presented at the First National Conference on Alcohol and AIDS, Tucson, AZ, 1989.

Dermen, K.H. AND Cooper, M.L. Sex-related alcohol expectancies among adolescents: II. Prediction of drinking in social and sexual situations. Psychol. Addict. Behav. 8: 161-168, 1994.

Dermen, K.H. AND COOPER, M.L. Inhibition conflict and alcohol expectancy as moderators of alcohol's relationship to condom use. Exp. Clin. Psychopharmacol. 8: 198-206, 2000.

Dermen, K.H., Cooper, M.L. and Agocha, V.B. Sex-related alcohol expectancies as moderators of the relationship between alcohol use and risky sex in adolescents. J. Stud. Alcohol 59: 71-77, 1998.

Dermen, K.H. AND ThOMAs, S.N. A brief motivational approach to reducing drinking and sexual risk behavior among college students. Paper presented at the annual meeting of the Research Society on Alcoholism, Denver, CO, May 2000.

Desiderato, L.L. and Crawford, H.J. Risky sexual behavior in college students: Relationships between number of sexual partners, disclosure of previous risky behavior, and alcohol use. J. Youth Adolesc. 24: 55$68,1995$.

DE VINCENZI, I. A longitudinal study of human immunodeficiency virus transmission by heterosexual partners: European study on heterosexual transmission of HIV. New Eng. J. Med. 331: 341-346, 1994.

DiLorio, C., Dudley, W.N. and Soet, J. Predictors of HIV risk among college students: A CHAID analysis. J. Appl. Biobehav. Res. 3: 119134, 1998.

Douglas, K.A., Collins, J.L., Warren, C., Kann, L., Gold, R., Clayton, S., Ross, J.G. And KolBe, L.J. Results from the 1995 National College Health Risk Behavior Survey. J. Amer. Coll. Hlth 46: 55-67, 1997.

Epstein, S. Aggregation and beyond: Some basic issues on the prediction of behavior. J. Pers. 51: 360-392, 1983.

Fortenberry, J.D., OrR, D.P., Katz, B.P., Brizendine, E.J. AND Blythe, M.J. Sex under the influence: A diary self-report study of substance use and sexual behavior among adolescent women. Sex. Trans. Dis. 24: 313-319, 1997.

Freimuth, V.S., Hammond, S.L., Edgar, T. and McDonald, D.A. et al. Factors explaining intent, discussion and use of condoms in first-time sexual encounters. Hlth Educ. Res. 7: 203-215, 1992.

Fromme, K., D’Amico, E.J. and Katz, E.C. Intoxicated sexual risk taking: An expectancy or cognitive impairment explanation? J. Stud. Alcohol 60: 54-63, 1999. 
Gayle, H.D., Keeling, R.P., Garcia-Tunon, M., Kilbourne, B.W., Narkunas, J.P., Ingram, F.R., Rogers, M.F. and Curran, J.W. Prevalence of the human immunodeficiency virus among university students. New Eng. J. Med. 323: 1538-1541, 1990.

George, W.H., Stoner, S.A., Norris, J., Lopez, P.A. and Lehman, G.L. Alcohol expectancies and sexuality: A self-fulfilling prophecy analysis of dyadic perceptions and behavior. J. Stud. Alcohol 61: 168-176, 2000.

Gold, R.S., Karmiloff-Smith, A., Skinner, M.J. and Morton, J. Situational factors and thought processes associated with unprotected intercourse in heterosexual students. AIDS Care 4: 305-323, 1992.

Graves, K.L. Risky behavior and alcohol use among young adults: Results from a national survey. Amer. J. Hlth Prom. 10: 27-36, 1995.

Hale, R.W., Chan, D.F., Nagy, K. and Stockert, N. Seventeen-year review of sexual and contraceptive behavior on a college campus. Amer. J. Obstet. Gynecol. 168 (6, Pt 1): 1833-1837, 1993.

Halpern-Felsher, B.L., Millstein, S.G. and Ellen, J.M. Relationship of alcohol use and risky sexual behavior: A review and analysis of findings. J. Adolesc. Hlth 19: 331-336, 1996.

Harvey, S.M. AND Beckman, L.J. Alcohol consumption, female sexual behavior and contraceptive use. J. Stud. Alcohol 47: 327-332, 1986.

Justus, A.N., Finn, P.R. And Steinmetz, J.E. The influence of traits of disinhibition on the association between alcohol use and risky sexual behavior. Alcsm Clin. Exp. Res. 24: 1028-1035, 2000.

Kalichman, S.C., Heckman, T. and Kelly, J.A. Sensation seeking as an explanation for the association between substance use and HIV-related risky sexual behavior. Arch. Sexual Behav. 25: 141-154, 1996.

Kotloff, K.L., Tacket, C.O., Wasserman, S.S., Bridwell, M.W., Cowan, J.E., Clemens, J.D., Brothers, T.A., O’Donnell, S.A. And Quinn, T.C. A voluntary serosurvey and behavioral risk assessment for human immunodeficiency virus infection among college students. Sex. Trans. Dis. 18: 223-227, 1991.

Kraft, P. And Rise, J. Contraceptive behaviour of Norwegian adolescents. Hlth Educ. Res. 6: 431-441, 1991.

Kraft, P., Rise, J. and Traeen, B. The HIV epidemic and changes in the use of contraception among Norwegian adolescents. AIDS 4: 673$678,1990$.

LANG, A.R. The social psychology of drinking and human sexuality. J. Drug Issues 15: 273-289, 1985.

LeIGH, B.C. The relationship of sex-related alcohol expectancies to alcohol consumption and sexual behavior. Brit. J. Addict. 85: 919-928, 1990.

Leigh, B.C. and Schafer, J.C. Heavy drinking occasions and the occurrence of sexual activity. Psychol. Addict. Behav. 7: 197-200, 1993.

Leigh, B.C., Schafer, J. and Temple, M.T. Alcohol use and contraception in first sexual experiences. J. Behav. Med. 18: 81-95, 1995.

Leigh, B.C. and Stall, R. Substance use and risky sexual behavior for exposure to HIV: Issues in methodology. Amer. Psychol. 48: 1035$1045,1993$.

Lewis, D.F., Goodhart, F. and Burns, D. New Jersey college students' high-risk behavior: Will we meet the health objectives for the year 2000? J. Amer. Coll. Hlth 45: 119-126, 1996.

Lowry, R., Holtzman, D., Truman, B.I., Kann, L., Collins, J.L. and KolBe, L.J. Substance use and HIV-related sexual behaviors among US high school students: Are they related? Amer. J. Publ. Hlth 84: 1116-1120, 1994.

McCabe, M.P. and Collins, J.K. Measurement of depth of desired and experienced sexual involvement at different stages of dating. J. Sex Res. 20: 377-390, 1984.

McClelland, G.H. and Judd, C.M. Statistical difficulties of detecting interactions and moderator effects. Psychol. Bull. 114: 376-390, 1993.

MacDonald, N.E., Wells, G.A., Fisher, W.A., Warren, W.K., King, M.A., Doherty, J.A. AND BowIE, W.R. High-risk STD/HIV behavior among college students. JAMA 263: 3155-3159, 1990.
MacDonald, T.K., Fong, G.T., Zanna, M.P. and Martineau, A.M. Alcohol myopia and condom use: Can alcohol intoxication be associated with more prudent behavior? J. Pers. Social Psychol. 78: 605-619, 2000a.

MacDonald, T.K., MacDonald, G., Zanna, M.P. and Fong, G. Alcohol, sexual arousal, and intentions to use condoms in young men: Applying alcohol myopia theory to risky sexual behavior. Hlth Psychol. 19: 290-298, 2000b.

MacDonald, T.K., Zanna, M.P. And Fong, G.T. Why common sense goes out the window: Effects of alcohol on intentions to use condoms. Pers. Social Psychol. Bull. 22: 763-775, 1996.

McEwan, R.T., McCallum, A., Bhopal, R.S. and Madhok, R. Sex and the risk of HIV infection: The role of alcohol. Brit. J. Addict. 87: 577584, 1992.

Meilman, P.W. Alcohol-induced sexual behavior on campus. J. Amer. Coll. Hlth 42: 27-31, 1993.

Miller, B.C., Christopherson, C.R. and King, P.K. Sexual behavior in adolescence. In: Gullotta, T.P. And Adams, G.R. (Eds.) Adolescent Sexuality: Advances in Adolescent Development, Vol. 5, Thousand Oaks, CA: Sage, 1993, pp. 57-76.

Nisbett, R. And Ross, L. Human Inference: Strategies and Shortcomings of Social Judgment. Century Psychology Series. Upper Saddle River, NJ: Prentice Hall, 1980.

O’Leary, A., Goodhart, F., Jemmott, L.S. and Boccher-Lattimore, D. Predictors of safer sex on the college campus: A social cognitive theory analysis. J. Amer. Coll. Hlth 40: 254-263, 1992.

Patrick, K., Covin, J.R., Fulop, M., Calfas, K. And Lovato, C. Health risk behaviors among California college students. J. Amer. Coll. Hlth 45: 265-273, 1997.

Pepe, M.V., Sanders, D.W. and Symons, C.W. Sexual behaviors of university freshmen and the implications for sexuality educators. J. Sex Educ. Ther. 19: 20-30, 1993.

Project MATCH Research Group. Matching alcoholism treatments to client heterogeneity: Project MATCH posttreatment drinking outcomes. J. Stud. Alcohol 58: 7-29, 1997.

Project MATCH Research Group. Matching alcoholism treatments to client heterogeneity: Project MATCH three-year drinking outcomes. Alcsm Clin. Exp. Res. 22: 1300-1311, 1998.

Reinisch, J.M., Hill, C.A., Sanders, S.A. and Ziemba-Davis, M. Highrisk sexual behavior at a midwestern university: A confirmatory survey. Fam. Plan. Perspect. 27: 79-82, 1995.

ReIs, H.T. AND GABLE, S.L. Event sampling and other methods for studying daily experience. In: ReIs, H.T. And JudD, C.M. (Eds.) Handbook of Research Methods in Social and Personality Psychology, New York: Cambridge Univ. Press, 2000, pp. 190-222.

Santelli, J.S., Brener, N.D., Lowry, R., Bhatt, A. and Zabin, L.S. Multiple sexual partners among U.S. adolescents and young adults. Fam. Plan. Perspect. 30: 271-275, 1998.

Senf, J.H. And Price, C.Q. Young adults, alcohol and condom use: What is the connection? J. Adolesc. Hlth 15: 238-244, 1994.

Sheeran, P., Abraham, C. And Orbell, S. Psychosocial correlates of heterosexual condom use: A meta-analysis. Psychol. Bull. 125: 90-132, 1999.

STEELE, C.M. AND Josephs, R.A. Alcohol myopia: Its prized and dangerous effects. Amer. Psychol. 45: 921-933, 1990.

Testa, M. And Collins, R.L. Alcohol and risky behavior: Event-based analyses among a sample of high-risk women. Psychol. Addict. Behav. 11: 190-201, 1997.

Traeen, B. and Kvalem, I.L. Sex under the influence of alcohol among Norwegian adolescents. Addiction 91: 995-1006, 1996.

Wechsler, H., Davenport, A., Dowdall, G., Moeykens, B. and Castillo, 
S. Health and behavioral consequences of binge drinking in college: A national survey of students at 140 campuses. JAMA 272: 1672-1677, 1994.

Wechsler, H., Dowdall, G.W., Davenport, A. and Castillo, S. Correlates of college student binge drinking. Amer. J. Publ. Hlth 85: 921926, 1995.
Wechsler, H., Rigotti, N.A., Gledhill-Hoyt, J. And Lee, H. Increased levels of cigarette use among college students: A cause for national concern. JAMA 280: 1673-1678, 1998.

Wiley, D.C., James, G., Jordan-Belver, C., Furney, S., Calsbeek, F., Benjamin, J. and Kathcart, T. Assessing the health behaviors of Texas college students. J. Amer. Coll. Hlth 44: 167-172, 1996. 